\title{
Analysis of the total toxicity of some technogenically disturbed soils using bioassays
}

\author{
Ta Thi Anh Van, Violetta Klyueva, and Kristina Degtyareva \\ Belgorod State National Research University, 308015, Belgorod, Russia
}

\begin{abstract}
In laboratory conditions, the analysis of the total toxicity of some technogenically disturbed soils of the Belgorod region was carried out using bioassays: Daphnia magna Straus, green algae Scenedesmus quadricauda (Tiger) and Lepidium sativum L. As a result of the experiments, the degree of toxicity of the tested soils was established. The conducted studies confirm the high information content when using three bioassays for the analysis of total soil toxicity.
\end{abstract}

Keywords: toxicity, bioassays, disturbed soils.

\section{Introduction}

A significant increase in the accumulation of pollutants in the environment as a result of uncontrolled human economic activity leads to disruption of ecological systems, serious changes in the natural environment [1]. Soil is one of the main environments that is subject to negative anthropogenic impact, as it is able to concentrate not only pollutants that enter it directly, but also those that are in the air, water and plants. Therefore, studies of soil quality and the degree of soil contamination can provide effective solutions to improve its quality and ecosystems in general.

The analysis of the total toxicity of the soil allows us to identify the quality of the soil, the degree of contamination and the cause-and-effect relationships of active human intrusion into the natural course of natural processes and the intensity of self-cleaning processes. It involves the use of several analytical methods to assess the quality of the soil, of great importance among which is biotesting using test organisms, which are used to identify the total toxicity of the test environment [1]. The use of physico-chemical methods provides information only about the amount of chemical elements in the environment, but not about the toxic effect that it can have on living organisms, while bioassays quickly makes it possible to obtain a comprehensive response of the soil to pollution [2]. However, bioassay does not cancel the physico-chemical method, but complements it and makes monitoring and environmental assessment more integral, giving an adequate answer to whether the test environment is toxic [3].

It is known that different test organisms differ in their sensitivity to toxicants. In this regard, to increase the objectivity of the study of the toxicity of an object, a series of biotests is used, in which test organisms belong to different taxonomic groupsv[4].

\footnotetext{
*Corresponding author:1221268@bsu.edu.ru
} 
The purpose of these studies is to analyze the general toxicity of some technogenically disturbed soils of the Belgorod region to obtain primary information about their quality and potential ability to self-repair. To study the soil quality, bioassays were used on Daphnia magna Straus crustaceans, green algae Scenedesmus quadricauda (Tiger) and higher plants Lepidium sativum L.

The toxicity of some soil samples was determined using three different bioassays. Soil toxicity is a manifestation of the negative effects of various substances and their mixtures that inhibit, stimulate, cause genetic changes or kill organisms in the soil [5]. The advantages of plant biotests are efficiency, environmental friendliness, short testing period, cost-effectiveness and objectivity of the results.

\section{Materials and methods}

The object of the study: 10 soil samples selected according to a standard method from a depth of 5-10 cm in September 2020 on the territory of Belgorod (No. 1 - the bank of the Vezelka River, Levoberezhnaya Street, No. 2 - Memory Park - Khmelnitsky Avenue 133, No. 3 Belgorod International Airport named after V. G. Shukhov - Bogdan Khmelnitsky Avenue 166, No. 4 Kindergarten No. 86, Chapaev Street, 3, No. 5 - Central city beach, Severo - Donetskaya Street, No. 6-Belgorod Railway Station, Vokzalnaya Street 1, No. 7 Dubovoe and Alekseyevka (No. 8 - Park of culture and recreation, ul. Frunze 66A, No. 9 Park, next to the workshop EFKO, №10 - Kindergarten No 50 - 3-I Krasnogorskaya St. 35).

The General toxicity study was carried out on soil extract in acute experiments the according to the standard method (Method of measuring the amount of Daphnia magna Straus for determination of toxicity of drinking water, fresh water natural and waste water, water extracts from soils, soils, sewage sludge, production and consumption waste using the direct invoice method)

This technique is based on determining the mortality of daphnia when exposed to toxicants present in the test medium, compared with the control culture in a sample that does not contain toxicants $[6,7]$.

In the method of FR. 1. 39. 2007. 03223 (Biological control methods), biotesting was performed using Scenedesmusquadricanda algae, based on the registration of changes in the number of cells, in which both stimulating and inhibitory effects on the growth of algae were recorded in comparison with the control culture in samples that did not contain toxicants (control) $[8,9,10]$.

The method of biotesting using cress Lepidiumsativum or the method of phytotesting is based on the observation of seed germination, growth and morphological characteristics after 96 hours of exposure $[11,12,13]$.

Statistical reliability of differences in quantitative indicators established in the experimental and control series of tests for the same time period was carried out according to the Student's criterion.

\section{Results and discussion}

The results of the analysis of the total toxicity of various soil samples are shown in Figure 1 . 


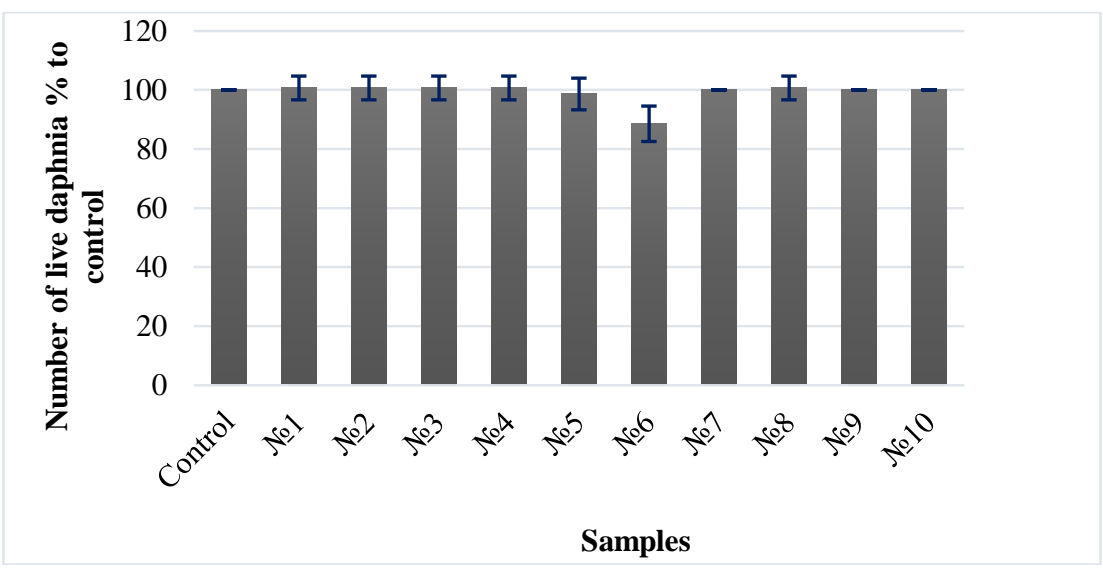

Fig. 1. The number of live Daphnia magna Straus as a percentage of the control after $96 \mathrm{~h}$ of exposure

According to the survival rate of crustaceans, the difference with the control exceeded $10 \%$, sample No. 6 had a weak toxic effect on daphnia. The remaining samples did not show significant differences from the control, that is, they did not have toxicity.

The results of soil biotesting on algae are presented in Table 1.

Table 1. The result of soil biotesting on algae after $96 \mathrm{~h}$ of exposure

\begin{tabular}{|c|c|c|c|c|}
\hline Samples & $\begin{array}{c}\text { Average } \\
\text { number of } \\
\text { cells, } \mathbf{1 0} \text { cl./ml }\end{array}$ & Deviation, \% & $\mathbf{t}_{\mathbf{d}}$ & $\begin{array}{c}\text { Reliability of } \\
\text { differences according } \\
\text { to the Student's } \\
\text { criterion }\end{array}$ \\
\hline Control & $43.2 \pm 0.71$ & 100 & - & + \\
\hline №1 & $56.2 \pm 1.50$ & 131.41 & 13.7 & + \\
\hline №2 & $51.4 \pm 0.95$ & 119.22 & 12.1 & + \\
\hline №3 & $56.85 \pm 1.15$ & 132.09 & 17.5 & + \\
\hline №4 & $56.3 \pm 2.29$ & 133.43 & 9.5 & + \\
\hline №5 & $37.88 \pm 2.33$ & 91.57 & 3.8 & + \\
\hline №6 & $33.35 \pm 1.11$ & 78.48 & 13 & + \\
\hline №7 & $50.35 \pm 1.20$ & 117.4 & 8.9 & + \\
\hline №8 & $49.45 \pm 3.20$ & 119.9 & 3.3 & + \\
\hline №9 & $48.55 \pm 2.31$ & 115.83 & 3.8 & + \\
\hline №10 & $38.15 \pm 1.56$ & 90.43 & 5.2 & + \\
\hline
\end{tabular}

It was shown that sample No. 6 with a decrease in the number of cells by more than $20 \%$ of the control had an inhibitory effect, samples No. 1, No. 3, and No. 4 with an increase in the number of cells by more than $30 \%$ had a stimulating effect (Fig. 2). 


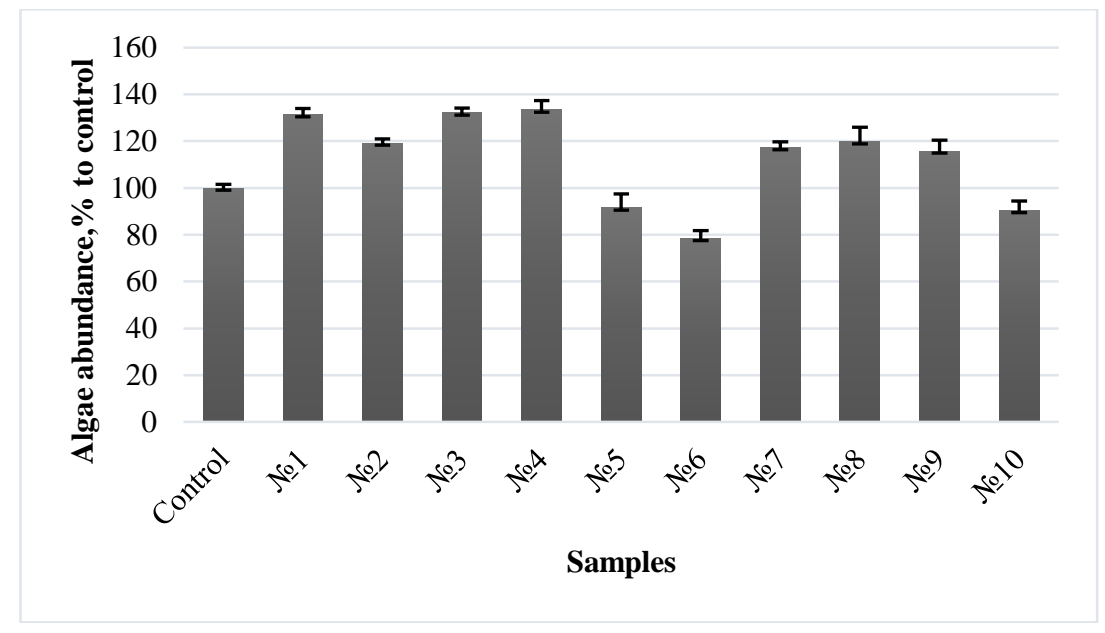

Fig. 2. The number of algae cells as a percentage of the control after $96 \mathrm{~h}$ of exposure

Similar results were obtained when analyzing the toxicity of some technogenically disturbed soils by bioassay using watercress.

In sample No. 6, the seed germination rate was less than $90 \%$, which indicates low toxicity in this sample. All other samples have a seed germination rate of more than $90 \%$, which indicates that no toxicity was observed in them according to the seed germination criterion (see tab. 2.).

Table 2. Germination of watercress in 4 days

\begin{tabular}{|c|c|c|}
\hline Samples & $\begin{array}{c}\text { Seed } \\
\text { germination } \\
\text { rate (\%) }\end{array}$ & $\begin{array}{c}\text { Toxicological characteristics } \\
\text { of the soil }\end{array}$ \\
\hline Control & 96.67 & - \\
\hline №1 & 92.22 & - \\
\hline №2 & 98.89 & - \\
\hline №3 & 90 & - \\
\hline №4 & 92.22 & - \\
\hline №5 & 95.56 & $+/-$ \\
\hline №6 & 88.89 & - \\
\hline №7 & 90 & - \\
\hline №8 & 94.44 & - \\
\hline №9 & 90 & - \\
\hline №10 & 94.44 & \\
\hline
\end{tabular}

To obtain comparable results based on the results of testing, the toxicity index of the evaluated factor was calculated for each biological bioassay:

$$
\mathrm{TI}=\mathrm{TF}_{0} / \mathrm{TF}_{\mathrm{C}}[14]
$$


where $\mathrm{TF}_{0}$ is the value of the registered test object in the experiment; $\mathrm{TF}_{\mathrm{C}}$ - the value of the registered test object in the control. The results are presented in Table 3 and 4 and in Figure 3.

Table 3. Results of soil bioassay on the length of cress roots after 4 days

\begin{tabular}{|c|c|c|c|c|c|}
\hline Samples & $\begin{array}{c}\text { Average } \\
\text { root length }\end{array}$ & TI & $\mathbf{t}_{\mathbf{d}}$ & $\begin{array}{c}\text { Reliability of } \\
\text { differences } \\
\text { according to the } \\
\text { Student's criterion }\end{array}$ & $\begin{array}{c}\text { Toxicological } \\
\text { characteristics of } \\
\text { the soil }\end{array}$ \\
\hline Cont. & $39.20 \pm 2.66$ & 1 & - & + & $+/-$ \\
\hline №1 & $32.58 \pm 2.58$ & 0.84 & 2.4 & + & $+/-$ \\
\hline №2 & $28.89 \pm 1.33$ & 0.72 & 4.8 & + & +- \\
\hline №3 & $26.81 \pm 0.9$ & 0.66 & 6.2 & + & - \\
\hline №4 & $35.3 \pm 0.81$ & 0.86 & 2 & - & $+/-$ \\
\hline №5 & $36.84 \pm 1.59$ & 0.92 & 1.1 & + & - \\
\hline №6 & $29.78 \pm 0.56$ & 0.73 & 4.8 & + & - \\
\hline №7 & $40.46 \pm 1.52$ & 1 & 0.6 & + & $+/-$ \\
\hline №8 & $31.26 \pm 2.74$ & 0.81 & 2.9 & - & - \\
\hline №9 & $34.00 \pm 3.51$ & 0.9 & 1.7 & + & + \\
\hline №10 & $36.29 \pm 2.04$ & 0.92 & 1.2 & + & + \\
\hline
\end{tabular}

Table 4. Results of soil bioassay on the length of cress shoots after 4 days

\begin{tabular}{|c|c|c|c|c|c|}
\hline Samples & $\begin{array}{c}\text { The length } \\
\text { of the } \\
\text { shoots }\end{array}$ & TI & to & $\begin{array}{c}\text { Reliability of } \\
\text { differences } \\
\text { according to the } \\
\text { Student's criterion }\end{array}$ & $\begin{array}{c}\text { Toxicological } \\
\text { characteristics of } \\
\text { the soil }\end{array}$ \\
\hline Cont. & $19.60 \pm 0.85$ & 1 & - & + & \\
\hline №1 & $19.28 \pm 1.24$ & 1 & 0.3 & + & - \\
\hline №2 & $19.35 \pm 0.89$ & 0.99 & 0.3 & + & - \\
\hline №3 & $17.71 \pm 0.97$ & 0.91 & 2.1 & + & - \\
\hline №4 & $18.32 \pm 0.79$ & 0.93 & 1.6 & + & - \\
\hline №5 & $19.7 \pm 0.91$ & 1.01 & 0.1 & + & $+($ growth \\
\hline №6 & $21.06 \pm 1.81$ & 1.12 & 1 & + & - \\
\hline №7 & $19.33 \pm 0.71$ & 0.98 & 0.4 & + & - \\
\hline №8 & $19.23 \pm 1.72$ & 1.02 & 0.3 & + & - \\
\hline №9 & $18.51 \pm 1.06$ & 0.96 & 1.2 & + & - \\
\hline №10 & $20.35 \pm 1.78$ & 1.08 & 0.6 & + & + \\
\hline
\end{tabular}




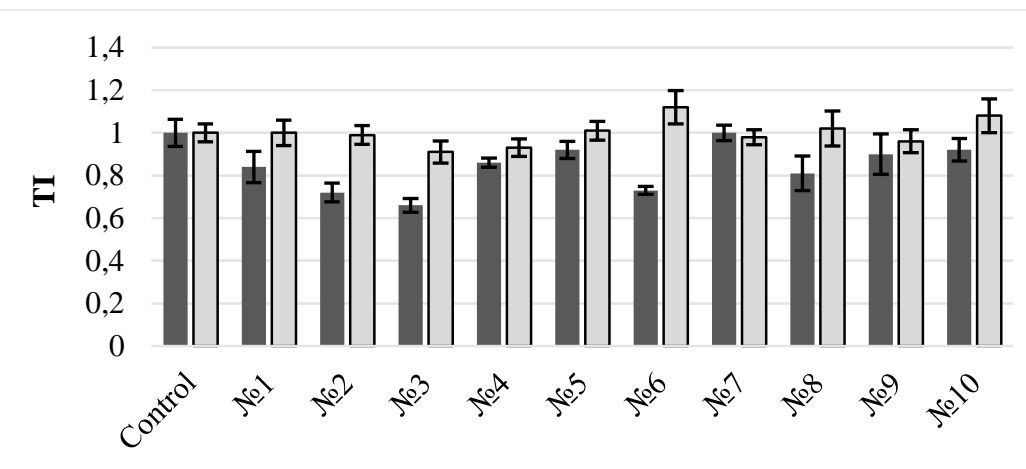

Samples

- IT by root length $\quad \square$ IT by the length of the shoots

Fig. 3. Toxicity index of the studied soils by the length of the roots and shoots of watercress

To determine the degree of toxicity of the studied soils, the toxicity scale was used (Table 5)

Table 5. The scale of soil toxicity [14]

\begin{tabular}{|c|c|}
\hline Toxicityclass & TI \\
\hline VI (stimulation) & $>1,10$ \\
\hline V-norm & $0,91-1,10$ \\
\hline IV-lowtoxicity & $0,71-0,90$ \\
\hline III-averagetoxicity & $0,50-0,70$ \\
\hline II-hightoxicity & $<0,50$ \\
\hline $\begin{array}{c}\text { I-ultra-high toxicity, causing death } \\
\text { of the test object }\end{array}$ & $\begin{array}{c}\text { The environment is not suitable for } \\
\text { the life of the test object }\end{array}$ \\
\hline
\end{tabular}

Along the length of the roots, in sections №1, №2, №6, №8, №9 Toxity Index in the range of 0.71-0.9 had a low toxicity, at the site No. 3 Toxity Index in the range of 0.5-0.7, an average toxicity was noted.

According to the value of the length of the shoots, Toxity Index at sites No. 6Toxity Index more than 1.10 had a stimulating effect, all other samples within the normal range of $0.91-1.10$, they did not have toxicity.

\section{Conclusion}

The analysis of the total toxicity of some technogenically disturbed soils by bioassay methods revealed the degree of toxicity of the tested soil samples.

According to the results of the study, the most sensitive test organism for this type of sample is cress. The results of the bioassay show that the extract from the soil No. 6 , had toxicity on daphnia, extracts from the soil №1, №3, №4, №6, №8 exerted toxicity on algae and soil samples №1, №2, №3, №6, №8, №9 they were toxic to watercress.

During the bioassay, the test cultures of daphnia, algae, and watercress used complement each other. 
1. E.A. Minakova, T.A. Kandrabaeva, R.R. Sugaepova Materials of the International Scientific and Practical Conference Natural sciences and humanities in the modern world. P.171-175 (2020).

2. T. Yakovyshyna Universum: chemistry and biology. Scientific journal. 8(16), 3 (2015).

3. D. V. Seifert. Modern problems of biomonitoring and bioindication. Materials of the AllRussian Scientific and Practical Conference with international participation, 1 (Kirov, 2010)

4. T. V. Bardina, M. V.Chugunova, V. V.Kulibaba, V. I.Bardina. Biosfera 12(1), 1 (2020). 5. O. A. Lyashenko, M. A. Kustikova, L. A. Konopelko, E. A. Bykovskaya, I. V. Timofeeva, A.V. Vasilevskaya, A. S. Mayurova. ITMO University, 51 (2019)

6. Toxicological control methods. Method of measuring the amount of Daphniamagna Straus for determining the toxicity of drinking, fresh natural and waste water, water extracts from soils, soils, sewage sludge, production and consumption waste by direct counting. (2014).

7. Y.M. Polyak, L.G.Bakina, N.V.Mayachkina, I.V. Drozdova., A.V. Kaplan, D. L Golod. Pochvy i okrujaiushaya sreda. 4, 231 (2018).

8. Biological control methods. Method for determining the toxicity of water, water extracts from soils, sewage sludge and waste by changing the level of chlorophyll fluorescence and the number of algae cells. FR 1.39.2007.03223.

9. M.A. Mikheev, M.A. Ipatova. Materials of the XVII All-Russian Scientific and Practical Conference with International participation. 2 ( VyatGu, Kirov 2019).

10. A.V. Vasiliev. Electronic scientific Journal "Oil and Gas Business". 4, 242 (2012).

11. O.F. Filenko. Biotesting of environmental quality using hydrobionts. Section of the big laboratory of Hydrobiology (Moskow 2015).

12. V.A. Medvedev. Materials of the XVII All-Russian Scientific and Practical Conference with International participation 2 (VyatGu, Kirov 2019).

13. S.D Borisova. Biotesting: methodological guidelines for performing laboratory work. (2015).

14. E.I. Popova. Modern problems of science and education. 4, 216 (2016). 